\title{
Ergonomic effects on workers of selected healthcare areas of King Abdulaziz Medical City, National Guard Hospital, Riyadh Saudi Arabia
}

\author{
Fayz Al Shahry, ${ }^{1}$ Wejdan Mohammed Alhuwail ${ }^{2}$, Ghadah Mohammed Alshehri ${ }^{2}$, Jihan Ali \\ Al-Motairi ${ }^{2}$, Smily Jesupriya Victor Paulraj ${ }^{3 *}$, Fatma Othman ${ }^{4}$ and Galib Algamdi ${ }^{5}$ \\ ${ }^{1}$ Assistant Professor. CAMS, KSAU-HS, Consultant Neurorehabilitation Service, King Abdulaziz Medical City, \\ ${ }^{2}$ Student, Occupational Therapy, CAMS, KSAU-HS, Riyadh Saudi Arabia \\ ${ }^{3}$ Senior lecturer, CAMS, KSAU-HS, Riyadh Saudi Arabia \\ ${ }^{4}$ Assistant Professor CAMS, KSAU-HS, Riyadh Saudi Arabia \\ ${ }^{5}$ Occupational Therapy Program Manager CAMS, KSAU-HS, Riyadh Saudi Arabia
}

\begin{abstract}
Ergonomics' is composed of two words which are 'ergo' a Greek word meaning work, and 'nomics' which means study. Ergonomics factors that contribute to the health are inappropriate lighting, tools design, chair design, heavy lifting and repetitive motion and others. These factors can cause musculoskeletal disorders (MSDs). The aim of this study was to assess ergonomic effect on workers of ultrasound and microbiology areas in King Abdulaziz Medical City, (KAMC)-Riyadh. The second objective of this study was to identify the ergonomic factors and the presence of work related injuries, also to compare awareness of ergonomics of work sites of health workers. This study was a cross sectional quantitative study conducted at KAMC,National Guard Hospital (NGH), the sample size for workers in radiology department was 27, and the sample size for workers in the laboratory was 27. Two questionnaires distributed among laboratory and radiology workers constructed of questions and demographic data were adapted for our study to determine the effect of ergonomics, the most common physical problems that workers experience in their workstation, and the awareness of ergonomic among the health care workers 18 participants (40.0\% of the total) from the Microbiology-technicians were completed the questionnaire and were 27 participants (60.0\%) form the Ultrasoundsonographers completed the questionnaire. There was an ergonomic effect on gender for microbiology technicians ( $p$-value was 0.043). Moreover, the ultrasound-sonographers had a significant association between gender and pain
\end{abstract}

\section{ARTICLE INFORMATION:}

Corresponding Authors: shahryf@hotmail.com

Received $1^{\text {st }}$ Aug, 2018

Accepted after revision 23 $3^{\text {rd }}$ Nov, 2018

BBRC Print ISSN: 0974-6455

Online ISSN: 2321-4007 CODEN: USA BBRCBA

Thomson Reuters ISI ESC / Clarivate Analytics USA

: Mono of Clarivate Analytics and Crossref Indexed Journal Mono of $C R$

NAAS Journal Score 2018: 4.31 SJIF 2017: 4.196

- A Society of Science and Nature Publication, Bhopal India 2018. All rights reserved.

Online Contents Available at: http//www.bbrc.in/

DOI: $10.21786 / \mathrm{bbrc} / 11.4 / 9$ 
Fayz Al Shahry et al.

related to work ( $\mathrm{p}$ value $<0.001$ ). Awareness however, in microbiology technicians, was found to be $83 \%$ who knew the meaning of ergonomics and 85\% in ultrasound sonographers. In conclusion, there was a significant effect of ergonomic on sonographers and microbiology technician. The study showed a good level of knowledge and awareness about ergonomics, however, still there is a quiet high percentage of them who did not receive health education on ergonomics and also a high percentage who aren't implementing ergonomics. There is a need for educational and implementation empowerment programs in this regard.

KEY WORDS: ERGONOMIC, ULTRASOUND, MICROBIOLOGY, OCCUPATIONAL THERAPY, MUSCULOSKELETAL DISORDERS

\section{INTRODUCTION}

'Ergonomics' is composed of two words which are 'ergo' a Greek word meaning work, and 'nomics' which means study, Tayya et al. (1997) Pao et al. (2001) have defined ergonomics as a branch of science which analyses the optimal relationship between workers and their environment. It is also described as a system that the workers interact with the work environment, the tasks and the workplace, (Brooks 1998). Ergonomics significantly developed during World War II, and now includes design, medicine, and computer science, (Goyal et al., 2009) as it includes a variety of conditions that can affect workers in different aspects such as health and comfort. Besides, it also has factors that are contributing to the health such as lighting, tools design, chair design, heavy lifting and repetitive motion and others. These factors can cause injuries and problems related to muscles, tendons or nerves which can lead to musculoskeletal disorders (MSDs), (Jaffar et al., 2011, Mcatamney et al., 2017).

Musculoskeletal disorders MSDs are injuries and disorders that affect the nerves and soft tissues which are muscles, tendons, ligaments and joints. According to Yelin et al. (1999) the majority of the old workers were disabled due to MSDs, which were also observed among female care givers. Therefore, poor ergonomics have an impact on the worker's health and can lead to occupational health injuries. According to Lee, ergonomics is promoting compatibility between humans and systems, (Lee 2017).

Considering the workers' limitations and capabilities by fitting environments, and tasks to improve the productivity and safe work performance reduce costs due to work injuries. There are many types of jobs which require moderate to heavy physical work such as health care workers, engineers, food industry workers, manual workers, and office workers and other service staff. Inappropriate workplace design, tools and equipment machine lead to fatigue, frustrate, and hurt the workers. The most extreme risk factors which affect the workers on the worksite are the uncomfortable static position, repetitive motion, vibration, heavy lifting, temperature, and lighting. Many studies have shown that work injuries and pain caused by risk factors of ergonomics result from frequent bending, twisting, heavy physical activities, heavy (manual) lifting and whole-body vibration,
(Estryn-Behar et al. 1990, Kuiper et al. 1999 and Lee 2017).

One of the most arduous professionals that require overload on the body, forced position, and long working hours are working in health care. Doctors, Nurses, Radiologists, Dentists and other groups in the healthcare professions show a high incidence of work-related injuries and pain result from a singular (acute) event to gradual events of repetitive movement which lead to handling patients and equipment. Several studies are showing high-risk factors of ergonomics among healthcare workers. The primary factors which can increase musculoskeletal injuries and induce pain among health care workers are load (weight and size of materials, the force needed to push or pull, a position of handholds, and a shape of handles) and posture (disadvantageous positions of the arms and legs, forward bend and twist of the trunk) and environment (inappropriate floor conditions, insufficient equipment, inadequate lighting and thermal conditions, and time pressure). Ergonomics have a high impact on the worker, and poor ergonomics may lead to MSDs. The job of health care workers and other professionals demand a tremendous physical load to improve the productivity of healthcare and hence adequate quality; the ergonomics prevents the risk factors and work-related injuries. Proper office ergonomics contribute to increase workers' effectiveness and reduce musculoskeletal injuries that associated with office working. Recent studies pointed out that poor ergonomics of the above areas lead to MSDs and pain on the workers.

Work in radiology area demands physical tasks such as patient's transfer and using imaging equipment and computer-related task. Accordingly, improved ergonomics of the radiology department will contribute to reduce the risk of work-related injuries and provide the safety when dealing with patients, (Siegal et al. 2010, Ruess et al. 2003). In regards to laboratory work, it needs a prolonged standing position. Because of that laboratory healthcare workers are more exposed to MSDs and poor ergonomics can lead to pain in the different area of the body, (Agrawal et al. 2015).

There is a paucity of data on the ergonomics of places involving patient care, sites of diagnosis of diseases such as radiology and laboratories. Hence the present study was planned and proposed so that the evidence created from the study will give light to the ergonomic effects 
on workers of selected healthcare areas. This study was aimed to assess the ergonomic effect on workers of ultrasound and microbiology technicians of areas in KAMCRiyadh, and to identify the ergonomic factors and the presence of work-related injuries, it also compared the ergonomical awareness of the workers.

\section{MATERIAL AND METHODS}

This was a cross-sectional quantitative study conducted at National Guard Hospital (NGH), in Riyadh over 6-months period from Aug to Nov 2017. The study was approved by the Institutional Review Board at King Abdullah International Medical Research Center (KAIMRC). The study included technicians from two different areas. The first area is radiology; the inclusion criteria of radiologist workers were a technician working at Ultrasound areas (which include sonographers works in general Ultrasound, Mammogram areas, Echo areas, and OB-GYN areas), including all ages and both genders. The exclusion criteria were the other areas such as Magnetic Resonance Imaging (MRI) and Computed Tomography (CT). The other area is a laboratory, the inclusion criteria were microbiology technician, including all ages and both gender. The exclusion criteria were workers in other areas of laboratory such as hematology. With a population of 60 technicians, 50\% margin of error of 95\% of confidence level, the required sample size was calculated as 53. Selection of samples based on the departments. The sample size for workers in the radiology department is 18 , and the sample size for workers in the laboratory is 27 .

A self-developed questionnaire was used to collect the data from the workers. The questionnaires constructed of yes or no questions (microbiology department 37 questions and radiography department 30 questions) and demographic data was adapted for our study to determine the most common physical problems that workers experience in their workstation, the effect of ergonomics, and the awareness of ergonomic among the healthcare workers. The procedure of the study done after identification of the subjects and the consent form was obtained from the participants before enrolling in the study. The questionnaires were distributed randomly among laboratory and radiology workers. All the data collected were analyzed by SPSS version 21 software, and descriptive statistics were used to summarize the data.

\section{RESULTS AND DISCUSSION}

\section{STUDY POPULATION}

We identified 45 microbiology-technicians and Ultrasound-sonographers. The Microbiology-technicians

\begin{tabular}{|l|l|l|}
\hline \multicolumn{3}{|l|}{ Table 1. Participant characteristics } \\
\hline & Male & Female \\
\hline Microbiology-technicians (N) & 4 & 14 \\
\hline Percentage (\%) & 22.2 & 77.8 \\
\hline Years of experience (mean) & 2.67 & \multicolumn{2}{|l|}{} \\
\hline Ultrasound-sonographers ( N) & 4 & 23 \\
\hline Percentage (\%) & 14.8 & 85.2 \\
\hline Years of experience (mean) & 10.22 \\
\hline
\end{tabular}

were 18 participants (40.0\%) completed the questionnaire, with a mean age of 26 years $(S D=3.97)$. The Ultrasound-sonographers were 27 participants (60.0\%) completed the questionnaire, with a mean age of 35 years ( $S D=7.17$ ) (see Table 1 for further information).

\section{Ergonomic Effects on Health Care Workers}

\section{Ergonomic Effects on Microbiology-technicians}

A significant association between gender and pain related to work (p-value was 0.043). We found that 50\% of male and $92 \%$ of female have pain or discomfort related to work. We reveals that the most common pain positions among both genders were lower back (16\%), followed by Feet heel (14\%), Neck and shoulder blade $(12 \%)$, Shoulders and headache (10\%), dry eyes (9\%), eye strain (7\%), depression and wrist (5\%). We found that $(60 \%)$ of both genders reported that the pain started at the end time of the workday (p-value was 0.017). Table 2 \& figure 1 shows that most common activities of daily living that affected by work-related pain were social activities and sleep (33\%), family demands (27\%), work productivity and health maintenance (16\%). The results show that, the most common factor the participants were complaining of was chair type (55\%), followed by chair width (44\%), smell (38\%), narrow space (33\%), excessive noise (27\%), table (16\%), high light and computer monitor and contact pressure (11\%). Regarding the techniques and changes that technician used to decrease the pain related to work, we found that most of them applying stretching exercise (50\%), massage (44\%), and the rest either take painkillers, smoking or

Table 2. Activities that affected by work injuries on microbiology technicians

\begin{tabular}{|l|l|l|l|l|}
\hline & $\mathrm{n}$ & Total & $\begin{array}{l}\text { Pearson } \\
\text { Chi-Square }\end{array}$ & $\mathrm{p}$-value \\
\hline Social activity & 6 & 18 & $.643^{\mathrm{a}}$ & 0.432 \\
\hline Sleep & 6 & 18 & $.643^{\mathrm{a}}$ & 0.423 \\
\hline Family demands & 5 & 18 & $.020^{\mathrm{a}}$ & 0.888 \\
\hline Work productivity & 3 & 18 & $.257^{\mathrm{a}}$ & 0.612 \\
\hline Health maintenance & 3 & 18 & $4.114^{\mathrm{a}}$ & 0.043 \\
\hline
\end{tabular}




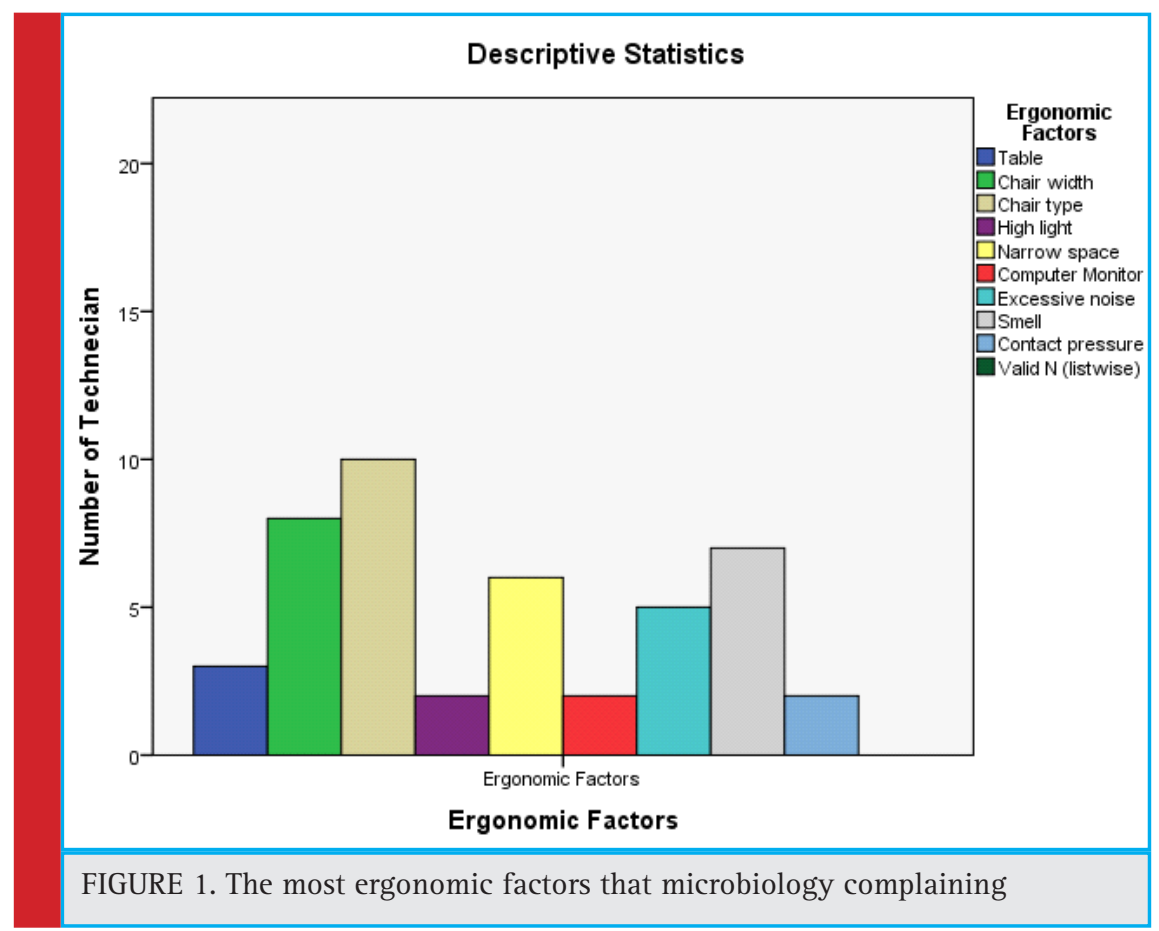

nothing. None of them try to visit Occupational therapy clinics to get help and education about some techniques and changes that help to decrease and eliminate pain and injuries related to work. As a solution to reduce and eliminate pain related to work, we found that most of technician suggest to add regular short breaks (50\%), decrease the work hours (33\%), increase the number of technicians (33\%), add regular stretching exercise (33\%), made changes in the workplace (22\%), and training and education about proper ergonomics (22\%).

\section{Ergonomic Effects on Ultrasound-sonographers.}

A significant association between gender and pain related to work ( $p$-value $<0.001$ ). We found that $75 \%$ of the male and $86 \%$ of the female have pain or discomfort related to work. Fig 2 reveals that the most common pain positions among both genders were shoulders (17\%), followed by upper back (12\%), Neck (11\%), shoulder blade and lower back (10\%), foot heel and dry eyes (8\%), fingers (7\%), wrist (6\%), and elbow-forearm (5\%). We found that $(77 \%)$ of both genders reported that the pain started at the end time of the workday. Table 3 shows that most common activities of daily living that affected by work-related pain were family demands (48\%), work productivity (40\%), social activities (37\%), sleep (33\%), and health maintenance (18\%). The results show that, the most common factor the participants were complaining of was chair type (44\%), followed by heavy tools (40\%), computer monitor (29\%), repetitive motion (25\%), narrow space and poor light and chair width (14\%), excessive noise and high light (7\%), and table
(3\%) (Figure 2). Regarding the techniques and changes that sonographers used to decrease the pain related to work, we found that most of them doing massage (62\%), stretching exercise (55\%), ask for sick leave and go to physician (14\%), and go to physiotherapy clinics (7\%). None of them try to visit Occupational therapy clinics to get help and education about some techniques and changes that help to decrease and eliminate pain and injuries related to work. As a solution to minimize and eliminate pain related to work, we found that most of technicians suggest having training and education

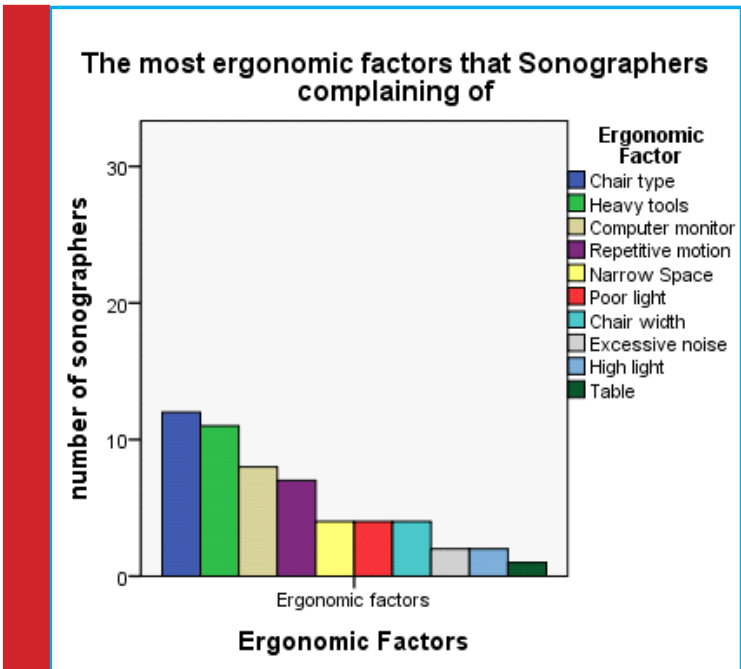

FIGURE 2. The most ergonomic factors that sonographers complaining 


\begin{tabular}{l} 
Table 3. Activities that affected by work injuries on \\
sonographers \\
\hline
\end{tabular}

about proper ergonomics (62\%), increasing the number of sonographers and adding regular stretching exercise (59\%), adding regular short breaks (40\%), decreasing the work hours (25\%), and made changes in the workplace (18\%).

\subsection{Awareness}

Regarding the awareness in Microbiology technician, we found that 83\% who know the meaning of ergonomics, $88 \%$ who think poor ergonomics lead to health risk, 50\% who get an education about proper posture and body mechanics, and 44\% who implemented the appropriate posture and body mechanics. In Ultrasound sonographers, we found that $85 \%$ who know the meaning of ergonomics, $81 \%$ who think poor ergonomics lead to health risk, 66\% who get an education about proper posture and body mechanics, and 55\% who implemented the proper posture and body mechanics. (see Table 4 for further information).

The current study findings showed that there are significantly higher feelings of pain and discomfort in female compared to male participants. This finding is

Table 4. Awareness of Ergonomics

\begin{tabular}{|c|c|c|c|c|c|c|c|}
\hline & & & \multicolumn{2}{|c|}{ Gender } & \multirow[t]{2}{*}{ Total } & \multirow{2}{*}{$\begin{array}{l}\text { Pearson Chi- } \\
\text { Square }\end{array}$} & \multirow[t]{2}{*}{ p-value } \\
\hline & & & Male & Female & & & \\
\hline \multirow[t]{2}{*}{$\begin{array}{l}\text { Microbiology-technicians } \\
\text { Know the meaning of ergonomics }\end{array}$} & \multicolumn{2}{|l|}{ No } & 1 & 2 & 3 & $.257^{\mathrm{a}}$ & .612 \\
\hline & \multicolumn{2}{|l|}{ Yes } & 3 & 12 & 15 & & \\
\hline \multicolumn{3}{|l|}{ Total } & 4 & 14 & 18 & & \\
\hline \multirow[t]{2}{*}{ Poor ergonomics lead to health risk } & \multicolumn{2}{|l|}{ No } & 1 & 1 & 2 & & \\
\hline & \multicolumn{2}{|l|}{ Yes } & 3 & 13 & 16 & $1.004^{\mathrm{a}}$ & .316 \\
\hline \multicolumn{3}{|l|}{ Total } & 4 & 14 & 18 & & \\
\hline \multirow[t]{2}{*}{ Educated about proper posture } & \multicolumn{2}{|l|}{ No } & 1 & 8 & 9 & & \\
\hline & \multicolumn{2}{|l|}{ Yes } & 3 & 6 & 9 & $1.286^{\mathrm{a}}$ & .257 \\
\hline \multicolumn{3}{|l|}{ Total } & 4 & 14 & 18 & & \\
\hline \multirow[t]{3}{*}{ Implement proper body mechanics } & \multicolumn{2}{|l|}{ No } & 2 & 5 & 7 & & \\
\hline & \multicolumn{2}{|l|}{ Yes } & 1 & 7 & 8 & & \\
\hline & \multicolumn{2}{|l|}{ not applicable } & 1 & 2 & 3 & $.815^{\mathrm{a}}$ & .665 \\
\hline \multicolumn{3}{|l|}{ Total } & 4 & 14 & 18 & & \\
\hline \multirow[t]{2}{*}{$\begin{array}{l}\text { Ultrasound-sonographers } \\
\text { Know the meaning of ergonomics }\end{array}$} & \multicolumn{2}{|l|}{ No } & 1 & 3 & 4 & & \\
\hline & \multicolumn{2}{|l|}{ Yes } & 3 & 20 & 23 & $.386^{\mathrm{a}}$ & .534 \\
\hline \multicolumn{3}{|l|}{ Total } & 4 & 23 & 27 & & \\
\hline \multirow[t]{2}{*}{ Poor ergonomic lead to health risk } & \multicolumn{2}{|l|}{ No } & 1 & 4 & 5 & & \\
\hline & \multicolumn{2}{|l|}{ Yes } & 3 & 19 & 22 & $.131^{\mathrm{a}}$ & .718 \\
\hline \multicolumn{3}{|l|}{ Total } & 4 & 23 & 27 & & \\
\hline \multirow{2}{*}{\multicolumn{2}{|c|}{$\begin{array}{l}\text { Education about proper posture } \\
\text { Yes }\end{array}$}} & No & 2 & 7 & 9 & & \\
\hline & & 2 & 16 & 18 & $.587^{\mathrm{a}}$ & .444 & \\
\hline \multicolumn{3}{|l|}{ Total } & 4 & 23 & 27 & & \\
\hline Implement proper body mechanics & No & & 1 & 5 & 6 & & \\
\hline & Yes & & 1 & 14 & 15 & & \\
\hline & Not applicable & & 2 & 4 & 6 & $2.436^{\mathrm{a}}$ & .296 \\
\hline Total & & & 4 & 23 & 27 & & \\
\hline
\end{tabular}


by what had been previously reported in the literature, where the current human results concerning sex differences in experimental pain indicate greater pain sensitivity among females compared with males for most pain modalities. Additionally, many previous studies confirmed differences between genders and documented that women are more likely to experience musculoskeletal pain, (Cook et al., 2000, Ranasinghe et al., 2011).

In line with the study of Kaliniene et al. (2016), the current study showed that low back pain was the highest prevalent type of pain among the studied cohort. Additionally, a similar study conducted in Nigeria, and the authors found a high preponderance of upper and lower back pain Kayoed et al. (2013). The predominant involvement of the back, as observed in the current study, also is in agreement with reports of studies carried out in Roma, British Columbia, and United States, (Pike, et al. 1997, Mirk,et al 1999). Additionally, shoulder pain was among the most reported pain positions in the current study and in that of Kaliniene et al. (2016).

The current study finding highlighted the point that the lack of attention to ergonomics could lead to damage to the healthcare workers mainly in the form of musculoskeletal pain, stress injuries and eye strain which can lead to increase the workers' fatigue and decrease their productivity, and this is in accordance with what has been reported in the literature, (Hills et al., 2012). It has been demonstrated that MSDs are highly relevant in the context of work and that the current economic and social implications of these conditions are sizeable and often underestimated. There are some types of jobs and specific sectors including home care and nursing, represent a heightened risk of developing or aggravating MSDs. The converse of work environments that aggravate MSDs is that work context can also contribute to improvements in MSD outcomes mainly through ergonomic design and job duty adjustment, (Summers, et al., 2015).

In sonography, surveys done among American and Canadian sonographers in 1997 showed that the incidence of MSDs was 84\%; however, this incidence had increased to 90\% (Evans et al., 2009). An ergonomic workstation in sonography according to Baker and workers should include an ergonomic task chair, the chair should be easy to operate and be adjustable from a settled position, has a different lift, vinyl upholstery that is antimicrobial, a foot ring, special casters, and detailed instructions on its use for different types of studies, however, then they reported that the ergonomic features of the examination room equipment are only as good as the workers willingness to use them, (Baker et al., 2015).

The effectiveness key of these features is changing the worker work postures so that they maintain neutral postures for the majority of each examination. Comfort- able work postures can make any ultrasound workstation ergonomic, increase worker comfort, reduce injury risk, and impact the quality of patient care Baker et al. (2015). In the Nigerian study published in 2013, the most significant proportion of the participants reported that the use of chairs of low height and scanning chair both precipitated and aggravated their symptoms and feeling with pain, and they recommended the use of chairs and scanning tables of ideal heights that can decrease risks to musculoskeletal disorders associated with Ultrasonography, (Kayoed et al., 2013). The current study participants reported that their primary complaint and width. For ultrasound practitioners, to empower safe working practices the room should was from the chairs type be of an adequate size, (Tayyari et al., 1997) with lighting that does not cause glare on the monitor and heating that is suitable for the working conditions, (Baker et al., 2015 and Harrison et al., 2015).

This is in line with what the current respondents reported that narrow space is one of the common factors of their complaint. Massage and stretching exercises were the most common techniques and changes that sonographers in the current study used to decrease the pain related to work. Harrison and Harris (2015) in their review concluded that there are many factors involved in the prevention or the reduction of work-related MSDs for ultrasound practitioners. These factors include ergonomic issues, management of workload, psychosocial factors, physical factors and general fitness levels. Sunley et al. (2006) highlighted that ergonomics education for staff is essential to ensure that they are aware of best practice guidelines, ways of risk reduction to themselves and others and how to report and monitored pain and injury to ensure a long and healthy career, (Sunley et al., 2006). In the current study, results indicated that there is a shortage in ergonomics education; additionally, a high percentage of the respondents show their wish to receive education and training about ergonomics.

As per the results of several studies, the effects of occupational MSD interventions have been particularly strong when using a multi-branched intervention approach, combining physical exercise with another component, like worksite ergonomic changes, (Dawson et al., 2007, Holtermann et al., 2010). Unfortunately, none of the participants in the current study tried to visit occupational therapy clinics to get help and education about some techniques and changes that help to decrease and eliminate pain and injuries related to work. For healthcare workers, the previous study has shown that social, environmental factors such as work demands and social support are related to report MSDs, (Sorensen et al., 2011), which is almost the same with our study findings. Taken together with the evidence from previous interventions, these findings support intervention 
strategies that incorporate targeted changes to the physical and social work environment along with worker education.

For tackling MSDs at work, several preventive strategies can be taken. These prevention strategies primarily include risk assessment, and technical/ergonomic, organizational and person-oriented intervention. The secondary prevention strategy involves the identification and health monitoring of workers at risks, while the tertiary prevention strategy comprises a return to work actions, Mirk et al., 1999, EU-OSHA 2008. Suggestions of the current study respondents regarding a solution to decrease and eliminate pain related to work were within the context of those prevention strategies with adding regular short breaks being the highest scored suggestion. In line with this finding, a previous study identified that lack of rest breaks and use of facilities that are not ergonomic were the main contributing factors to workrelated MSDs Kayoed et al. (2013).

Some studies on sonographers have also linked regular breaks and reduced workload to reduced musculoskeletal symptoms, Schoenfeld et al. (1999). On the other hand, the work of Schoenfeld et al. (2013) did not find reduced scanning frequency to be associated with reduced symptoms among sonographers. Microbiology technicians participated in the current study showed a right awareness level with the term "ergonomics," a result which is better compared to the Nigerian research about awareness and knowledge of ergonomics among medical laboratory scientists, in which awareness of ergonomics and knowledge of gains of its right application was reduced, Oladeinde et al. (2015).

Additionally, it is better than what recorded elsewhere among computer users and manufacturing workers, (Loo et al., 2012, Shantakumari et al., 2012). The strengths of this study include that the data about ergonomics is scarce in Saudi Arabia, and to the best of our knowledge, this is the first study in Saudi Arabia that assesses the ergonomic effects on workers of selected healthcare areas. Second, healthcare workers especially those who participate in interventional procedures such as laboratory and radiology are well known and more prone to have musculoskeletal pain. Third, the data come from one of the biggest national hospitals in Riyadh. This study has some limitations including mainly the small sample size in microbiology technicians, and the participants were only from one healthcare institution. The results of this study may be further enhanced in the future by increasing the sample size.

\section{CONCLUSION}

In conclusion, there is a significant effect of ergonomic on sonographers and the laboratory technicians. The study showed a good level of knowledge and awareness about ergonomics; however, still, there is a quite high percentage of them who did not receive health education on ergonomics and also a high percentage who aren't implementing it. There is a need for educational and implementation empowerment programs in this regard.

\section{REFERENCES}

Agrawal Parul R, Maiya Arun G, Kamath V, Kamath A. (2015) Musculoskeletal Disorders among Medical Laboratory Professionals-A Prevalence Study. Journal of Exercise Science and Physiotherapy. 10(2):77.

Baker JP, Coffin CT. (2013) The importance of an ergonomic workstation to practicing sonographers. J Ultrasound Med. Aug; 32(8):1363-75.

Bergische Universität Wuppertal, pp. 72 Available at: www. dguv.de/content/prevention/campaigns/msd/review/ap_4_e.pdf

Brooks A. (1998) Ergonomic approaches to office layout and space planning. Journal of Facilities.; 16(3/4):73-78.

Cook C, Limerick BR, Chang S. (2000) The prevalence of neck and upper extremity musculoskeletal symptoms in computer mouse users. Int J Ind Ergon.; 26:347-56.

Dawson AP, McLennan SN, Schiller SD, Jull GA, Hodges PW, Stewart S. (2007) Interventions to prevent back pain and back injury in nurses: a systematic review. Occup Environ Med. Oct; 64(10):642-50.

Estryn-Behar M, Kaminski M, Peigne E, Maillard M, Pelletier A, Berthier C et al. (1990) Strenuous working conditions and musculo-skeletal disorders among female hospital workers. International Archives of Occupational and Environmental Health; 62(1):47-57.

EU-OSHA - European Agency for Safety and Health and Work, (2008) Work-related musculoskeletal disorders: prevention report, Publications Office of the European Union, Luxembourg,pp.106.Availableathttps://osha.europa.eu/en/ publications/reports/en_TE8107132ENC.pdf/view.

Goyal N, Jain N, Rachapalli V. (2009) Ergonomics in radiology. Clinical Radiology.; 64(2):119-126.

Harrison G, Harris A. (2015) Work-related musculoskeletal disorders in ultrasound: Can you reduce risk? Ultrasound. Nov; 23(4):224-30.

Hills DJ, Joyce CM, Humphreys JS. (2012) A national study of workplace aggression in Australian clinical medical practice. The Medical Journal of Australia. Sep 17; 197(6):336-40.

Holtermann A, Mortensen OS, Burr H, Søgaard K, Gyntelberg F, Suadicani P. (2010) Physical work demands, hypertension status, and risk of ischemic heart disease and all-cause mortality in the Copenhagen.

Jaffar N. (2011) A Literature Review of Ergonomics Risk Factors in Construction Industry. Procedia Engineering.; 20:89-97.

Kaliniene G, Ustinaviciene R, Skemiene L, Vaiciulis V, Vasilavicius P.(2016) Associations between musculoskeletal pain and work-related factors among public service sector computer 
workers in Kaunas County, Lithuania. BMC Musculoskelet Disord. 07; 17(1):420.

Kayoed I. Oke and A. A. Adeyekun. (2013) Patterns of Workrelated Musculoskeletal Disorders among Sonographers in selected Health Facilities in Nigeria. Journal of Applied Medical Sciences, vol. 2, no. 4, 67-76

Kevin Evans, Shawn Roll, Joan Baker .(2009) Work-Related Musculoskeletal Disorders (WRMSD) Among Registered Diagnostic Medical Sonographers and Vascular Technologists: A Representative Sample. Journal of Diagnostic Medical Sonography. Nov 1; 25(6):287-99.

Kuiper J, Burdorf A, Verbeek J, Frings-Dresen M, van der Beek A, Viikari-Juntura E. (1999) Epidemiologic evidence on manual materials handling as a risk factor for back disorders:a systematic review. International Journal of Industrial Ergonomics.; 24(4):389-404.

Lee K. (2017) Ergonomics in total quality management: How can we sell ergonomics to management? Journal of Ergonomics.; 48:5,547-558.

Loo HS, Richardson S, Alam S. (2012) Ergonomics issues in Malaysia. J Soc Sci. 8:61-5.

Magnavita N, Bevilacqua L, Mirk P, Fileni A, Castellino N. Work-related musculoskeletal complaints in sonologists. J Occup Environ Med. 1999 Nov; 41(11):981-8.

Mcatamney L, Corlett E. (2007) Ergonomic workplace assessment in a health care context. Institute for Occupational Ergonomics, University of Nottingham.; 35(9):965-978.

Michaelis, M., IPP-aMSE (2009) Identification and prioritisation of relevant prevention issues for work-related musculoskeletal disorders (MSD) - Work package 4 - Prevention approaches: evidence-based effects and prioritised national strategies in other countries,

Mirk P, Magnavita N, Masini L, Bazzocchi M, Fileni A. (1999) Frequency of musculoskeletal symptoms in diagnostic medical sonographers. Results of a pilot survey]. Radiol Med. Oct; 98(4):236-41.

Mirk, P L. Magnativa, M. Bazzocihi and A. Fileni. (1999) Frequency of musculoskeletal symptoms in diagnostic medical sonographers. Review of a pilot survey. Radiol. Med., 98(4), 236-41

Oladeinde BH, Ekejindu IM, Omoregie R, Aguh OD. (2015) Awareness and Knowledge of Ergonomics among Medical Laboratory Scientists in Nigeria. Ann Med Health Sci Res. Dec; 5(6):423-7.
Pao T, Kleiner B. (2001) New developments concerning the occupational safety and health act. Managerial Law; 43(1/2):138-146.

Pike, J. Russo, Berkowitz, J.P. Baker and V.A. Lessoway. (1997) The prevalence of musculoskeletal disorders and related work and personal factors among diagnostic medical sonographers. J Diag Medical Sonography, 13(5), 219-227.

Ranasinghe P, Perera YS, Lamabadusuriya DA, Kulatunga S, Jayawardana N, Rajapakse S, et al. (2011) Work related complaints of neck, shoulder and arm among computer office workers: a cross-sectional evaluation of prevalence and risk factors in a developing country. Environmental Health.; 10:70.

Ruess L, O'Connor S, Cho K, Hussain F, Houuard W, Slaughti $R$ et al. (2003) Carpal Tunnel Syndrome and Cubital Tunnel Syndrome: Work-Related Musculoskeletal Disorders in Four Symptomatic Radiologists. American Journal of Roentgenology.; 181:37-42.

Schoenfeld A, Goverman J, Weiss DM, Meizner I. (1999) Transducer user syndrome: an occupational hazard of the ultrasonographer. Eur J Ultrasound. Sep; 10(1):41-5.

Shantakumari N, Eldeeb RA, Sreedharan J, Gopal K. (2012) Awareness and practice of computer ergonomics among university students. Int J Med Health Sci.; 1:16-20.

Siegal D, Levine D, Siewert B, Lagrotteria D, Affeln D, Dennerlein J et al. (2010) Repetitive Stress Symptoms Among Radiology Technologists: Prevalence and Major Causative Factors.; 7:956-960.

Sorensen G, Stoddard AM, Stoffel S, Buxton 0, Sembajwe G, Hashimoto D. (2011) The role of the work context in multiple wellness outcomes for hospital patient care workers. J Occup Environ Med. Aug; 53(8):899-910.

Summers, K., Jinnet, K. \&t Bevan, S. (2015). Musculoskeletal disorders, workforce health and productivity in the United States. The Work Foundation. London, pp 40.

Sunley K. (2006) Prevention of Work-Related Musculoskeletal Disorders In Sonography. London: Society of Radiographers,

Tayyari F, Smith J .Occupational Ergonomics: principle and application. London: Chapman \& Hall; 1997. P. 4-214.

Yelin E, Trupin L, Sebesta D. (1999) Transitions in employment, morbidity, and disability among persons ages 51-61 with musculoskeletal and non-musculoskeletal conditions in the US, 1992-1994. Arthritis \& Rheumatism.; 42(4):769. 